\title{
Tchaikovsky, leitor de Dante: lugar da angústia e imaginação narrativa em Francesca da Rimini op.32 (1876)
}

\author{
Rafael Alves Pinto Junior (UFG, Goiânia, G0) \\ rafaeljuniorcefet@gmail.com
}

\begin{abstract}
Resumo: Este texto tem como objetivo discutir a estrutura do poema sinfônico Francesca da Rimini op. 32, composto por Piotr llyichTchaikovsky (1840-1893) em 1876, inspirado no Canto V do Inferno (1307) da Divina Comédia de Dante Alighieri (1265-1321). Interessa-nos observar como Tchaikovsky parte do texto poético de Dante - usando-o como fonte - e desenvolve uma narrativa musical que abre ao ouvinte outros planos do sensivel. Em Francesca, Tchaikovsky não se limita ao relato, mas cria, a partir dele, o seu próprio. Procuramos encontrar a operação-chave da estrutura compositiva da obra que parece ser a mímesis: se Dante descreve o que "vê" no real de sua ficção, Tchaikovsky descreve o que sente no "real" do espaço-tempo musical.
\end{abstract}

Palavras-chave: Tchaikovsky; Romantismo na música; música e literatura; representação e mímesis.

Tchaikovsky, reader of Dante: a place of anguish and imaginative narrative in Francesca da Rimini op.32 (1876)

Abstract: The paper aims at discussing the structure of Francesca da Rimini op. 32, a symphonic poem inspired on Canto V do Inferno (1307) from Divina Comédia of Dante Alighieri (1265-1321) and composed by Pyotr llyich Tchaikovsky (18401893) in 1876. Tchaikovsky uses Dante's poetic text as a source to develop a musical narrative that leads the listener to other planes of the sensitive. In Francesca, Tchaikovsky does not follow the story, but creates, from it, his own. The key to the compositional structure of the work seems to be the mimesis: if Dante describes what he "sees" in the reality of his fiction, Tchaikovsky describes what he feels in the reality of the space-time of music.

Keywords: Tchaikovsky; romanticism in music; music and literature; representation and mimesis.

\section{1 - Relação entre música e literatura}

\author{
Chorai, amantes, pois que chora Amor \\ Ouvindo qual razão o faz chorar. \\ Amor ouve mulheres a clamar, \\ Pelos olhos mostrando amarga dor, \\ Porque a morte vilã, causando horror, \\ Pôs em peito gentil seu trabalhar, \\ Gastando o que no mundo é de louvar, \\ Numa gentil mulher, mais do que o honor. \\ Dante ALIGHIERI (2011b)
}

Ao abordarmos a relação entre a música e a literatura, estamos diante de uma questão que virtualmente pode se desdobrar à extrema complexidade. 0 fato de músicos procurarem na literatura a matéria-prima para a composição musical - numa associação dos dois códigos - é digno de nota e merece ser investigado. Duas razões justificam esta investigação: a primeira se baseia no interesse, produto da percepção dos dois gêneros e da apreensão das similaridades entre ambos; a outra, mais decisiva, consiste na tentativa de investigar a narratividade no fenômeno musical, em que um estudo comparativo pode propiciar alguma contribuição.

Posiciono-me ao lado dos que estão convictos de que uma obra de arte abre, sempre, várias possibilidades': uma fonte privilegiada de expressão cujas propriedades estilisticas ou formais remetem tanto a uma percepção particular quanto a uma maneira de ver modificada pela experiência social e pela subjetividade da própria leitura.

Como qualquer obra de arte, a música está condicionada ao gradiente de intencionalidade do artista. Entendese por intenção o interesse do artista em produzir um determinado efeito junto ao público, visual para as artes 
plásticas, espacial para a arquitetura e sonoro para a música. Intenção que se transforma, particularmente, em cada caso, numa diretriz compositiva em que o autor se posiciona numa relação crítica com sua própria produção precedente, consciente ou inconscientemente, numa relação mental entre a obra e seu contexto. Sobre esta intenção da obra de arte, Baxandall coloca que;

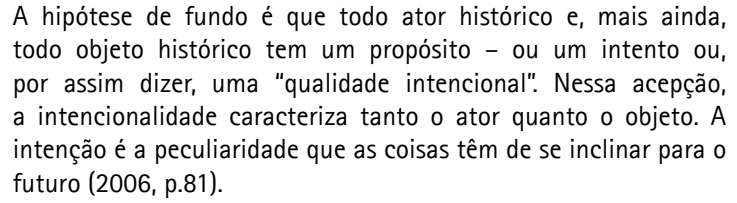
todo objeto histórico tem um propósito - ou um intento ou, por assim dizer, uma "qualidade intencional". Nessa acepção, a intencionalidade caracteriza tanto o ator quanto o objeto. A intenção é a peculiaridade que as coisas têm de se inclinar para 0 futuro (2006, p.81).

Quer sejamos observadores ou ouvintes, estamos inexoravelmente separados por um hiato temporal que vai da execução à conclusão da obra, ipso facto, estamos diante de um resultado acabado, produto de uma atividade em que pesam enormemente as variáveis subjetivas do autor, de cujo processo muito raramente possuímos dados que permitam uma análise factual. Para Laboissière (2007, p.26), esta posição temporal estabelece uma fenomenologia especifica na música: um processo que remete 0 artista à produção, que remete à subjetividade, que remete à potência do desejo, que, por sua vez, remete ao sistema de enunciação, comunicação e expressão. Como fato, temos a materialidade da obra, que, em determinado momento, o artista concluiu como acabada, decidindo que a imagem correspondia às necessidades que the deram origem. Como "leitores", esta posição não poderá ser absolutamente superada. Trata-se então de confrontar fontes, interpretações, pontos de vista. Operação de "leitura" a que se refere Baxandall (2006).

Se a obra de arte for uma peça musical, as dificuldades de "leitura" da obra podem parecer intransponíveis. Neste texto, enfrentaremos estas dificuldades como desafios. Barenboim (2009) observa que, para haver compreensão da interdependência de elementos na música, faz-se necessário o entendimento da relação entre espaço e tempo. Uma ação que cria um mundo significante próprioa partir de um sistema de notação ${ }^{2}$, que não é absolutamente determinista, antes surgindo como resultado da ação do compositor no ato da própria escritura, ao estabelecer sua repetibilidade, sem a qual a música não se tornaria possível.

Como poema sinfônico ${ }^{3}$, Francesca da Rimini op. 32 de Piotr Ilyich Tchaikovsky (1840-1893) coloca-nos uma dificuldade adicional: estruturando-se a partir de uma obra literária, encontra no texto poético seu vir-aser. Entretanto, o ponto que os une, ao mesmo tempo os diferencia: se Dante(1265-1321), através da poesia, constrói uma imagem do que "vê", Tchaikovsky constrói uma imagem do que sente. Se a imaginação do poeta cria o caráter e o destino do personagem na poesia, a imaginação do compositor atualiza o texto, inserindo-o em seus próprios contextos. Procura captar o conceitochave que desse unidade à ideia de representação da narrativa. Essa chave é a mímesis.

\section{2 - Uma alma atormentada}

$\mathrm{Na}$ produção musical erudita ocidental, o texto literário sempre esteve estreitamente ligado à música, pelo menos desde Claudio Monteverdi (1567-1643), com obra como Madrigais e L'Orfeo estreados em Mântua em 1607, estabelecendo uma relação inseparável entre texto e música com o papel do libreto tanto nas óperas quanto nas cantatas religiosas ou profanas. Com a criação do Poema Sinfônico no século $X I X$, o entendimento do texto literário toma uma outra dimensão, inédita até então. A literatura desaparece para aparecer na música e desdobrar-se num horizonte de significados como matriz de uma obra sem texto. Como gêneros específicos, tanto a música quanto a literatura estabelecem suas próprias regras compositivas, dispõem de ferramentas estruturais autônomas e criam, cada uma à sua maneira, seus limites de expressão em que a mesma linha imaginária que aproxima a música do texto escrito, estabelece suas diferenças. Neste sentido, a linguagem específica da obra de arte - literária, visual ou musical - não é somente um meio de expressão à disposição do artista, mas constitui uma "atmosfera" legitimada pela tradição do ensino e pela prática social do artista que tem um peso considerável na prática artística, seja para afirmá-la, seja para contestá-la.

0 pensamento musical estava inscrito no texto do Dante que compartilhava com seus antecessores provençais a tessitura da rima polifônica. Um dado técnico da mais alta importância para a literatura daí em diante, como observa Campos:

0 conceito de "rima polifônica" tem a ver com as chamadas rimas separadas ou isoladas (rimas dissolutas ou estrampas) e com as estrofes (coblas) correspondentes, a saber, rimas que não se repetem no interior da estrofe, mas que comparecem na mesma posição em todas as demais (...). A partir de uma sonorização livre dentro de cada estrofe, sem rimas internas, constrói-se aqui um encadeamento fônico através da repercussão posicional das rimas, que entre-ecoam a distância, de uma estrofe para a outra (2003, p.39).

A partir de T. S. Eliot, Augusto de Campos salienta a "atualidade" e a facilidade da leitura do texto de Dante, fenômeno que tem a ver com a objetividade que o poeta compartilha com outros poetas da pré-Renascença como Chaucer (1343-1400), Villon (1431-1463), Arnaut de Riberac (1150-?) e Raimbaut de Vaqueyras (1180-1207):

0 estilo de Dante, afirma Eliot, tem uma lucidez particular uma lucidez poética, que se distingue da lucidez intelectual. 0 pensamento pode ser obscuro, mas a palavra é lúcida, ou antes, translúcida. Deve-se também tal 'facilidade' ao método poético da alegoria por ele empregado. A imaginação de Dante - prossegue Eliot - é uma imaginação visual. Seu propósito é 'fazer-nos ver o que ele viu'. Para tanto, ele utiliza uma linguagem muito simples, de poucas metáforas, pois alegoria e metáfora não convivem bem (op. cit. p.179).

Estas virtudes notoriamente não passaram despercebidas ao compositor que compreendeu com clareza o sentido do texto, mas colocando-se numa posição estética bastante diferente daquela do poeta. E trabalhando rumo a não a fazer o que o poeta viu, mas a fazer - (re)criar - o 
que a poesia criou, Tchaikovsky sentia, a partir do poema, um problema que não era somente dele, mas de vários outros artistas de sua época.

Analisando a relação entre a poesia e a música no romantismo europeu, Gonçalves observa que a expressão "direta" dos sentimentos manifestados pela música foi o principal correlato que tanto os poetas quanto os teóricos românticos tentaram estabelecer com a lírica. Nas palavras do autor:

\section{Algumas caracteristicas da linguagem musical, tais como seu efeito imediato e difuso no receptor, a ausência de um referente externo declarado e sua expressão melódica e harmoniosa, atraíram de maneira intensa a atenção dos poetas românticos no trabalho com a palavra (1994, p.100).}

Se a linguagem musical representou um canal para a ampliação das possibilidades expressivas da poesia no romantismo - ao menos como podemos ver em Keats (1975-1821) e Wordsworth (1770-1850), por exemplo o inverso pode ser dito para Francesca. Tchaikovsky fez o caminho inverso dos poetas ao optar pela estrutura da poesia sinfônica e a partir do texto poético de Dante encontrar material para sua música.

Em Tchaikovsky, a literatura constitui-se numa fonte privilegiada de inspiração, principalmente a dramaturgia shakespereana. Suas três obras baseadas em Shakespeare - A Tempestade, Romeu e Julieta e Hamlet - foram construídas a evocar a "atmosfera" da obra, seu efeito emocional e não a deter-se na narratividade do enredo ou de qualquer personagem. Em Francesca da Rimini isto não ocorre. Em parte por tratar-se de um fragmento de um texto - parte do Canto $V$ - e devido à força narrativa textual, a narratividade tomou uma dimensão de vital importância na música.

$\mathrm{Na}$ trajetória do compositor, Francesca da Rimini localiza-se num ponto bastante importante no contexto de sua produção artística e de sua vida pessoal: 1876 . Aos 36 anos e mesmo dotado desde a infância de um temperamento extremamente frágil e misantropo (BERBEROVA, 1948), Tchaikovsky já era um músico nacionalmente respeitado e um compositor maduro, dividindo seu tempo entre as atividades no Conservatório e a composição. Neste ano visita Paris acompanhado de seu irmão Modest (1850-1916), compõe o Quarteto de cordas op. 30, viaja a Bayreuth onde conhece Franz Liszt e, de volta à Rússia, é apresentado por Nikolai Rubinstein (1835-1881) à baronesa Nadyezhda von Meck (18311894). Fato que marcaria profundamente sua vida e sua produção. Depois de uma visita a sua irmã Alexandra em Verbovka e a Petrovich Shilovsky (1871-1924) em Ussovo, o compositor retorna a Moscou dominado por uma forte depressão. Atormentado pela "culpa" da homossexualidade, a depressão apertara o torniquete sobre o compositor. A partir da correspondência de Tchaikovsky, Wiley (2001) sugere que o compositor tinha plena consciência de que as consequências de suas preferências sexuais seriam no mínimo, constrangedoras: fonte de problemas no seu círculo social e no familiar. Optou então pela única saída que lhe pareceu cabivel: 0 casamento e a respeitabilidade social, que este, ainda que superficialmente, representava ${ }^{4}$. Em 18 de julho de 1877, casou-se com Antonina Ivanovna Milikova (1849-1917).

0 breve casamento terminou em setembro de 1877 e teve um único resultado: a infelicidade de ambos e uma crise emocional no compositor. Milikova e Tchaikovsky permaneceram legalmente casados, mas não voltaram a viver juntos. Para ele, este período correspondia ao que ele chamou de "minha breve insanidade" 5

Fazer um contraponto entre a produção do artista e sua vida pessoal está fora dos limites deste trabalho. Importa (re)conhecer aqui as circunstâncias da composição do opus 32 e contextualizar a atmosfera emocional que envolveu a obra. Reconhecer, com Wiley (2001), que a tempestade emocional na qual o compositor estava imerso fez com que ele encontrasse, no seu fazer musical, um caminho pela sublimação e a construção de um mundo de autoexpressão. Como consequência, sua produção tornar-se-ia, em alguns casos, idiossincraticamente confessional, ainda que esta confessionalidade pudesse indubitavelmente ser bastante estendida temporalmente, pelo menos da composição de Romeu e Julieta (1869) à Sinfonia n. 6 "Pathétique" (1893), última obra publicada pelo artista.

\section{3 - Francesca da Rimini}

Dedicada a Sergei Taneyev Ivanovich (1856-1915), Francesca da Rimini estreou em Moscou em 25 de fevereiro de 1877, conduzida por Nikolai Rubinstein, e foi um estrondoso sucesso. Taneyev havia sido o solista na estreia do Primeiro Concerto para Piano em 1875 em Moscou, e sua ligação com Tchaikovsky era de cordial amizade, mantida até a morte do compositor em 1893. Mas a ideia da obra não foi de Taneyev. Apesar da parcimônia dos dados sobreviventes, parece ter sido Modest Tchaikovsky quem sugeriu ao irmão em meados de 1876 a composição de um poema sinfônico, indicando alguns temas, entre eles Francesca. Respondendo ao irmão de Paris, em agosto de 1876, Piotr Tchaikovsky diz ter lido o texto de Dante e que havia ficado entusiasmado com o tema e com o texto. De volta a Moscou, não começou a trabalhar no Poema até pelo menos o final de setembro, devido em parte a outras atividades. Em outubro de 1876, escreve a Anatoli que havia escrito Francesca "febrilmente", que havia escrito com "amor" e que estava satisfeito com o resultado. Ainda em outubro, escreve a Karl Davydov (1838-1889) e pede que Francesca fosse incluída no próximo concerto da Sociedade Musical, informando que a instrumentação estaria concluída em algumas semanas. 0 que realmente ocorreu no início de novembro.

Estruturada na tonalidade Mi menor - correspondente à tristeza, agitação e inquietação - a peça começa com sons muito graves dos violoncelos e contrabaixos, seguidos pelos metais num Andante lugubre. Como um prefácio, 
Tchaikovsky não vai direto à narrativa do Canto V e expõe uma melodia que corresponde à de DANTE (2011a) diante do portão do Inferno:

Por mim se vai das dores à morada,
Por mim se vai ao padecer eterno,
Por mim se vai à gente condenada.

Moveu Justiça o autor meu sempiterno,

formado fui por divinal possança,

sabedoria suma e amor supremo.

No existir, ser nenhum a mim se avança,

nao sendo eterno, e eu eternal perduro:

Deixai, ó vós que entrai, toda a esperança!

Concebe um espaço sonoro e demarca um lugar narrativo como o de Dante, que, para Luchesi, foi concebido como uma noite da alma: a selva escura do pecado e dos suicidas, as palavras da porta, a ausência de estrelas, as tochas nos muros da cidade de Dite, perda de Deus, dor imensa (1994, p.35). A pulsação dos sopros é opressiva, arrastada, exprimindo a angústia diante da entrada dos condenados. Após esta introdução, sob um andamento piu mosso moderato, o compositor introduz o tema do martírio. Seu recurso formal é a alternância complexa dos timbres das cordas, madeiras e metais num concatenamento accelerando rumo a um sentido unívoco: a representação do que Dante viu no Segundo Círculo do Inferno, destinado aos que se entregaram à luxúria. Tchaikovsky não se interessa por seguir o texto do poeta literalmente, omitindo o encontro de Dante com Minos, detendo-se na contemplação do espetáculo do martírio das almas, condenadas a serem arrastadas perpetuamente num turbilhão inextinguível (DANTE, 2011a):

Em lugar de luz mudo tenho entrado:
Rugia, como faz mar combatido
Dos ventos, pelos impetos encontrado.

Da tormenta o furor, nunca abatido, perpetuamente as almas torce, agita, molesta, em seus embates recrescido.

Quando à borda do abismo as precipita,

Ais, soluços, lamentos vão rompendo.

Blasfema a Deus a multidão maldita.

As referências às imagens que Gustave Doré (1832-1883) fez para a Divina Comédia em 1857 (Ex.1a e 1b) e que o compositor evidentemente conhecia são inequívocas.
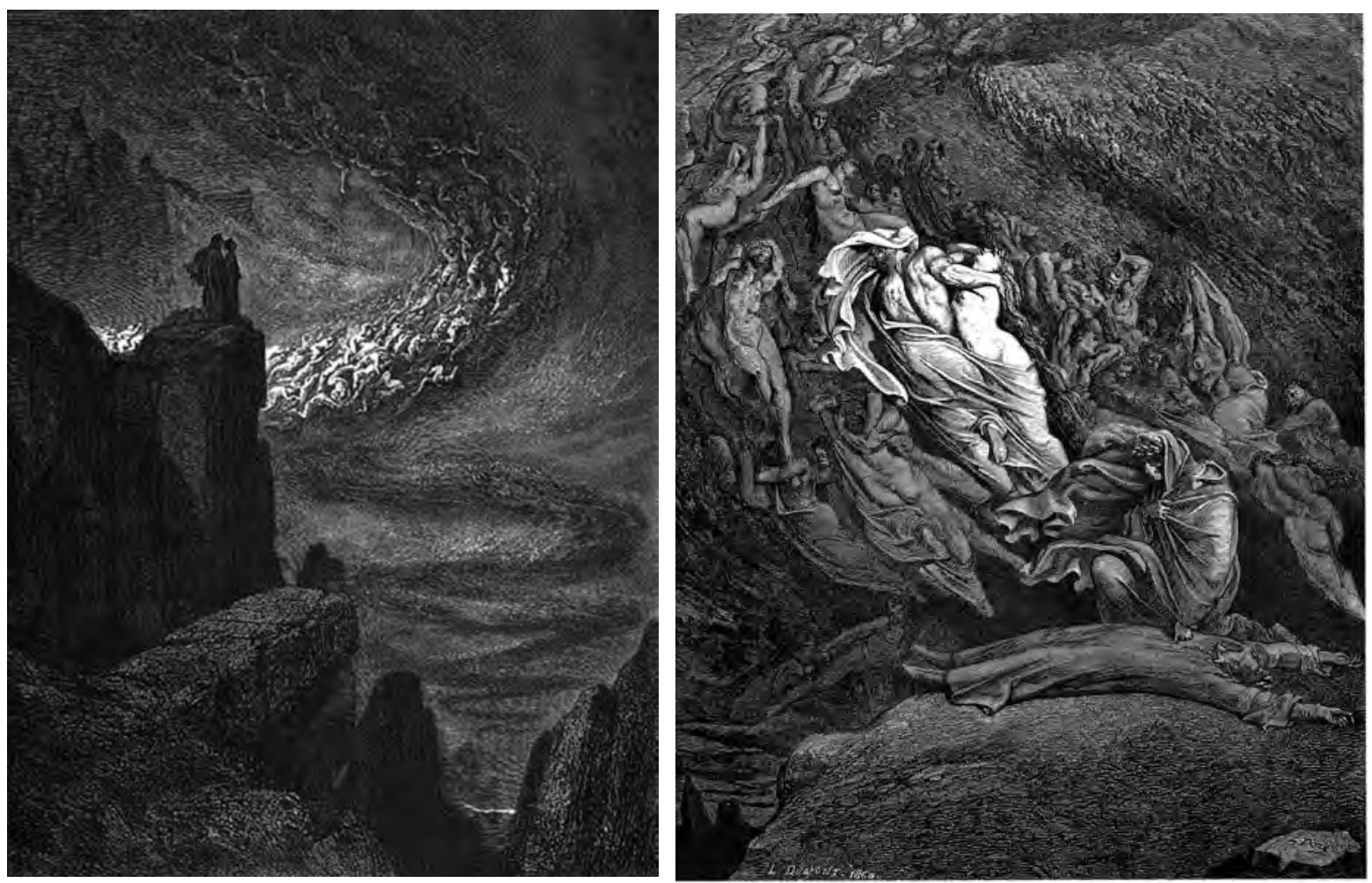

Ex.1a e $1 b$ - Ilustrações de Gustave Doré para a Divina Comédia, Canto V(1857) de Dante Alighieri: Portões do inferno e Inferno 
Como narrador, o poeta não é conhecedor do drama dos personagens e à medida que a jornada prossegue, registra os fatos mediante as imagens que encontra. Uma posição que Todorov $(1973$, p.237) nomeia como "visão de fora da narração". ${ }^{6}$

A trajetória narrativa do poema segue a disposição das penas, classificando e hierarquizando as almas segundo a natureza de suas transgressões (PASQUINI, 2005). Seguindo o preceito do contrapasso, que estabelece uma correspondência entre a transgressão cometida e a pena a ser cumprida, o martírio permanece eterno e não cambiável. No círculo dos condenados pela luxúria - e que não se arrependeram - a aplicação do contrapasso, além de estabelecer um lugar geográfico no Inferno, demarca uma característica identitária dos personagens. No caso de Francesca e Paolo, evidenciado pela união de suas almas que se esforçam para permanecerem juntos, enquanto a força do furacão se esforça na direção oposta. Esta contínua tensão entre o desejo da proximidade e a força do afastamento reflete o que Auerbach (1997) identifica como o destino individual das almas, preservado em plenitude no martírio de sua condenação. Presos numa situação psicológica que identifica sua pena, 0 contrapasso ilustra a perenidade do pecado, associando-o petreamente ao pecador, processo que fez de Francesca, um eloquente exemplo.

Ao representar o vórtice dos condenados, Tchaikovsky demonstra uma postura estética do sublime dinâmico conforme a formulada por Kant (2002). Neste espaço, não estamos interessados tanto no núcleo das posições relacionais entre o belo e o sublime, quanto no fato de como, na estrutura da peça, Tchaikovsky elaborou uma complexa fenomenologia da tempestade. Como observou Eco (2004, p.294), o que sacode a visão de quem contempla uma tempestade não é a impressão de uma infinita vastidão, mas sim de uma infinita potência, onde a natureza sensivel termina por ser humilhada: fonte de desconforto e angustia.

Diante do terrível espetáculo do furacão dos penitentes eternamente arrastados, Dante vê a aplicação de uma justiça divina. Tchaikovsky, por outro lado, é sacudido - e se esforça na escritura da peça para causar esta impressão nos ouvintes - pela potência de seus limites emocionais. Em Francesca, o furacão evidentemente representa o desejo e diante dele o compositor se mostra em toda sua insignificância. Como na natureza, o desejo é um poder cuja intensidade comporta a ideia de sua infinitude. Se em Dante, a razão julga a tempestade, apesar da falência da imaginação - sentimento de dor no sujeito (DANTE, 2011a) ${ }^{7}$ - Tchaikovsky mergulha no vendaval sem julgálo. Assume a realidade de sua existência, suspensa apenas durante o relato de Francesca.

Apesar de sólida, esta filiação à estética do Sublime não é literal, assim como não o é a leitura que o compositor faz do texto de Dante. Se em Kant, a apreensão do sublime dinâmico é um caminho de acesso à transcendência, Tchaikovsky nega, veementemente, qualquer possibilidade rumo a ela. Em Francesca não há transcendência, somente desejo e sofrimento. A imagem - ou a ideia da tempestade e das forças que ela representou para Tchaikovsky não são as mesmas que podemos facilmente constatar em outras obras de arte, como Monge Diante do Mar (1810), O Viajante sobre o mar de névoa (1818) de David Caspar Friedrich (1774-1840), ou Miranda (1916) de John Walterhouse (1849-1917).

Representação da tempestade que é, em suma, uma operação que se realiza mediante a mímesis. Conforme observa Costa Lima ao analisar os limites da ficção literária (2003, p.40-46) - no nosso caso, o texto de Dante, fonte da música - a especificidade discursiva da mímesis configura-se por sua submissão à tematização do imaginário. Por isso mesmo, escapa aos limites da atividade perceptual que regula as relações entre 0 sujeito e os modelos, tanto do "real' quanto do "sensível". Definindo-se como um processo criativo, ao considerar que é responsável pela produção de um imaginário que não repete o modelo, simplesmente resgatando, na semelhança aparente, a diferença latente, reapresentando o modelo organizado através de uma nova organização, evoca e apaga as cenas do "real" do texto de Dante ao mesmo tempo em que instaura seu lugar "sensivel" no espaço musical que constrói. Produção de uma encenação, que menos repete o modelo do texto poético do que implica a organização de uma resposta outra empreendida ao nível do sensivel (LIMA, 2007, p.76-77).

Tchaikovsky manipula exatamente estas ferramentas ao usar as imagens do texto de Dante, evocando-as para retirá-las de sua "realidade" e (re)escrevê-las mediante sua sensibilidade imaginária mediante a linguagem musical. Partindo do texto como construção de uma linguagem musical, entendida como uma ferramenta de elaboração textual, base da representação entre o texto literário e o texto sonoro, entre a mímesis e a verossimilhança, chega-se à construção de um texto (sonoro) a partir de outro texto (escrito), desenvolvendo uma ação que inscreve a mímesis num segundo nível de representação, considerando que somente indiretamente estabelece uma relação com o "real" do texto.

A representação do vendaval assinala na composição o lugar da angústia, num entendimento que vai além do temor da morte, significando a própria impossibilidade da existência do sujeito fora do continente do desejo, um conceito que Abbagnano identifica no pensamento de Heidegger:

E compreender tal impossibilidade significa compreender que todas as possibilidades da existência, consistentes em antecipações ou projetos que pretendem transcender a realidade de fato, só fazem reincidir na realidade de fato. Por isso, o verdadeiro significado da Angústia é o destino, isto é, a escolha da situação de fato como herança de que não se pode fugir e o reconhecimento da impossibilidade ou nulidade de qualquer outra escolha que não a aceitação da situação em que já se está. (...) Nesse sentido, Heidegger diz que a Angústia "liberta o homem das possibilidades nulas e torna-o livre para as autênticas" (2003, p.61) 


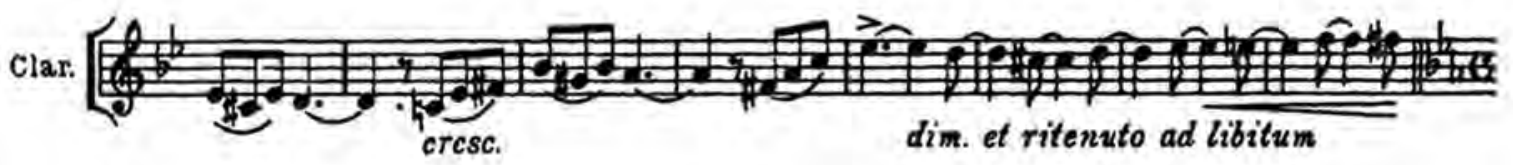

Ex. 2 - Francesca da Rimini op. 32 de Piotr Ilyich Tchaikovsky: tema do amor no clarinete

No meio do turbilhão das almas condenadas, Virgílio identifica várias personalidades associadas à luxuria, como Semíramis, Cleópatra, Páris, Helena e Tristão. Dante pede ao guia para falar com duas delas e tem 0 desejo atendido, e por um breve instante o suplício fica em suspenso. 0 vórtice se detém para que o poeta ouça o relato dos condenados. Quando atinge seu zênite, a angústia e sua representação (tormenta) cedem e Tchaikovsky dá voz ao relato correspondente à Francesca (1255-1285), e uma melodia muito triste - andante cantabile non troppo (Ex.2) - emerge de um silêncio abissal e um clarinete assume a narrativa introduzindo o tema do amor. Jogo cênico de contrastes: grandes massas orquestrais na representação da tempestade de um lado e melodia solo no plano narrativo pessoal do outro.

No poema, é Francesca da Rimini quem responde a Dante, contando o motivo de se encontrar naquela situação. Apaixonada por Paolo Malatesta (1246-1285), ela é forçada a casar-se com o irmão de Paolo, Gianciotto. 0 casamento, entretanto, não abafou seus sentimentos pelo então cunhado. Pelo contrário. Sua narrativa sugere que continuaram a se encontrar. Para Dante, Francesca diz que a história de amor de Lancelot a precipitou na situação em que se encontrava ${ }^{8}$, e já não tinha medo do sentimento que a arrastava ao amante, na confissão de um amor mútuo que terminaria no duplo assassinato pelo marido traído. A importância que Dante dá à narrativa de Lancelot como catalisador da situação dramática é digno de nota. Algo como se a arte desencadeasse a ação de mecanismos ocultos nos sujeitos e alheios à sua vontade, como uma engrenagem que move outra e assim sucessivamente, pondo em ação a tragédia do indivíduo ${ }^{9}$ numa teia que lhe escapa.

Certamente este foi um dos muitos pontos do texto de Dante que fascinaram o compositor. Como Francesca, ele se sentia arrastado a sentimentos que não podia controlar e que, por mais que fossem sufocados, não desapareceram. Como Francesca, ele se via preso ao desejo e sentia as pressões do forte vento da censura a afastá-lo de qualquer realização. Como ela, sentia o peso da recordação do tempo do desejo oprimido pelo tempo da separação.

Ao clarinete inicial, sucedem-se, em alternâncias e repetições entre os diversos timbres das cordas, madeiras e metais. Enquanto a melodia segue seu curso sustentada principalmente pelas cordas, Tchaikovsky teceu uma rede de escalas ascendentes dos sopros em segundo plano cuja única função é não deixar o ouvinte esquecer que a tormenta está suspensa, mas temporariamente. Uma rede de sombras, reflexos, névoas, fragmentos que emergem e caem. Fogos-fátuos à beira do abismo repleto de lampejos e vultos contorcidos.

0 pungente tema introduzido pelo clarinete e que domina a parte intermédia da composição assume a narratividade da tragédia da personagem:

\footnotetext{
Quando os doces suspiros só se ouviam,

Como, em que amor mostrar-vos ha querido

Os desejos, que ainda se escondiam?

Não há - disse - tormento mais dorido

Que recordar o tempo venturoso

$\mathrm{Na}$ desgraça. Teu mestre o tem sentido.

Mas porque de saber és desejoso,

Como nasceu a flor do nosso afeto,

Direi chorando o lance lastimoso. (DANTE, 2011a)
}

0 sentido trágico da melodia tem raízes na poesia que o compositor traduz como sentimento: elemento que reduz os amantes à totalidade do desejo. Denominador comum na produção romântica do século XIX, para Tchaikovsky, poesia e sentimento são sinônimos e igualmente responsáveis pela identidade de uma obra de arte.

No compositor, o texto do poema exerce à plenitude 0 sentido de desvelamento que Brandão atribui à obra de arte:

Tal experiência da verdade é o que muda o espectador e, portanto, é um outro tipo de verdade que se anuncia na obra de arte e que não pode ser compreendida como adequatio entre a obra e algo exterior a ela: é a verdade como desvelamento, produção do sentido, experiência do mundo da obra que se intromete e faz vacilar o mundo daquele que se envolve com ela (1999, p.3-4).

Tchaikovsky encontra este desvelamento da "verdade" da poesia quando, como leitor, confere-Ihe o sentido próprio da sobreposição do seu mundo com o mundo da obra que lê, pois a poesia the revela não somente o seu próprio "real", mas instrumentaliza o compositor a descobrir novos sentidos para sua expressão artística pessoal. 
Na conclusão da pungente linha melódica, Tchaikovsky conduz o ouvinte de volta ao ponto de partida e compõe a música como a rima polifônica dos provençais. 0 texto de Dante termina com a perda dos sentidos do narrador diante da tragédia. Tchaikovsky, ao contrário, constrói na peça uma arquitetura circular. A composição adquire a estrutura do círculo dos condenados e não termina na narrativa da personagem que retorna à inexorabilidade de seu destino: a tragédia de Francesca está completa. Não há saída, nem redenção para Francesca, Paolo ou Tchaikovsky. 0 canto de amor foi um breve relato suspenso no hiato do inextinguivel martírio. Conforme a estrutura da composição nos sugere, esta compreensão do destino nos remete a Heráclito (540-470 a. C), na afirmativa que faz Costa Lima ao observar, a partir de Auerbach, que o caráter de um homem é seu destino, significando que cada destino não é fortuito, pois o caráter de cada um de nós opera como a base de sua miséria, de sua fortuna ou de sua mediocritas (2007, p.748).

Com esta estrutura circular, o compositor deixa evidente sua compreensão do destino: fatalidade do ato de voltar a si mesmo. Historicidade autêntica, conforme Heidegger (2006) ao escolher o já escolhido, reapresentando uma ação já representada. Ao fim e ao cabo, Francesca da Rimini não é mais a narração do texto do poeta florentino. Tchaikovsky parte de Dante para encontrarse consigo mesmo. Olha para o espetáculo do vendaval e constrói um autorretrato.

\section{4 - Conclusão}

A audição de Francesca confronta o ouvinte com um autor que vai falar de si como sujeito da angústia. Seu "eu" aparece como resultado desta experiência estruturante, eixo em torno da qual se organizam os planos da narrativa musical. É deste modo que em Francesca emerge a narratividade de uma experiência da angústia nas suas diferentes dimensões, como relato da personagem do poema e como expressão dos dramas do compositor. Como experiência que envolve um sujeito - que deseja e ama permite a compreensão de aspectos como a sua origem e suas consequências: morte e expiação para Francesca e Paolo, angústia e inquietação para Tchaikovsky.

Apesar da opinião consensual na época - para Balakirev (1837-1910), por exemplo, Tchaikovsky havia atingido o apogeu de sua produção musical - dos méritos de Francesca, Tchaikovsky muda de ideia em relação à obra. Escrevendo ao próprio Balakirev em 24 de dezembro de 1882, o compositor fala de grandes "deficiências" da obra, em que "a relação da música com o programa não era intrínseca, mas apenas estranha". Mas sua opinião deve ser relativizada. 0 compositor estava num outro momento de sua vida quando escreveu a Balakiev, as turbulências de seu casamento fracassado com Milikova já se encontravam relativamente estabilizadas e ele se dedicava ao Trio para piano, violino e violoncelo em lá menor, op. 50, uma composição bem mais intimista e distante da grandiloquência de Francesca. Mas o sucesso de Francesca repudia o julgamento subjetivo de seu autor.

\section{Referências:}

ABBAGNANO, Nicola. Dicionário de Filosofia. São Paulo: Martins Fontes, 2003.

ALIGHIERI, Dante. Inferno: Canto III. Disponivel em: http://www.dominiopublico.gov.br/download/texto/gu000997.pdf. 2011a (Acesso em 20 de maio, 2011).

ALIGHIERI, Dante. Vita Nuova. Disponível em: http://www.consciencia.org/dante-alighieri-vida-nova. 2011b (Acesso em 20 de maio, 2011).

AUERBACH, E. Dante, o Poeta do Mundo Secular. Rio de Janeiro: Topbooks, 1997.

BARENBOIM, Daniel. A música desperta o tempo. São Paulo: Martins Fontes, 2009.

BAXANDALL, Michael. Padrões de Intenção. São Paulo: Companhia das Letras, 2006.

BERBEROVA, Nina. Tchaikovsky: Histoire Dune Vie Solitaire.Paris: Egloff, 1948.

BRANDÃO, Carlos A. L. A Formação do Homem Moderno Vista Através da Arquitetura. Belo Horizonte: Editora da UFMG: 1999.

CAMPOS, Augusto de. Invenção. São Paulo: Arx, 2003.

DORÉ, Gustave. Gates of hell. (Ilustração para A Divina Comédia, Canto V de Dante Alighieri). Disponivel em: www. focusfeatures.com (Acesso em 12 de maio, 2011).

Hell (Ilustração para A Divina Comédia, Canto V de Dante Alighieri). Disponível em: www.en.wikipedia.org

(Acesso em 12 de maio, 2011).

ECO, Humberto. História da Beleza. Rio de Janeiro: Record, 2004.

GONÇALVES, Aguinaldo J. Laokoon Revisitado. São Paulo: Edusp, 1994.

HEIDEGGER, M. Ser e Tempo. São Paulo: Vozes, 2006.

LABOISSIĖRE, Marília. Interpretação Musical. São Paulo: Annablume, 2007.

LIMA, Luiz Costa. Mímesis e modernidade: formas das sombras. São Paulo: Paz e Terra, 2003.

Trilogia do Controle. Rio de Janeiro, Topbooks, 2007. 
LUCCHESI, M. A. A Paixão do Infinito. Niterói: Cromos, 1994.

LUKÁCS, G. Teoria do Romance. Lisboa: Presença, 1982.

PASOUINI, E. e QUAGLIO, A. In: La Divina Commedia.Torino: Garzanti, 2005.

POZNANSKY, Alexander. Tchaikovsky: The Quest for the Man Interior.New York: Schirmer, 1991.

TCHAIKOVSKY, Piotr Ilyich. Francesca da Rimini. Disponivel em: http://www.wikipedia.org (Acesso em 12 de maio, 2011). WILEY, John Roland. Piotr Ilyich Tchaikovsky. New Grove Dictionary of Music and Musicians, Londres: Macmillan, 2001. ZAMPRONHA, E. Notação, representação e composição. São Paulo: Annablume, 2000.

\section{Notas}

1 Entendimento que descortina múltiplos sentidos e significados à volta da existência da obra de arte, ou o círculo hermenêutico nomeado por Ricoeur do qual nos fala BRANDÃo (1999, p.117): Para a hermenêutica de Ricoeur, o sentido não está nem dentro nem fora do texto [a obra de arte], mas circula entre múltiplos canais: o do autor, o do leitor, o da obra, o da tradição e o do público. Contudo, ela não visa a um saber absoluto, capaz de sintetizar todos estes múltiplos canais e dirigi-los a um sentido definitivo do texto e da obra, nem pretende um saber ou mediação total. 0 que dela se deriva são, apenas, mediações parciais que nos dão várias perspectivas da obra, semelhante ao cubismo, semelhante à percepção em que só podemos apreender perfis de um objeto.

2 Entendendo notação musical como um código ou sistema de informações através das quais os sons, ideias musicais, indicações de execução e andamento são registrados sob a forma de escrita, permitindo que a intenção do compositor seja restituída no ato da execução, conforme o colocado por ZAMPRONHA (2000, p.13).

3 Conforme o concebemos atualmente, o poema sinfônico surge com Franz Liszt (1811-1886) e seu desejo de expandir as obras de um único movimento além das formas já conhecidas e exploradas das Aberturas musicais. Entre 1849 e 1881, Liszt compôs 13 poemas sinfônicos -

Ce qu'on entend sur la montagne,_Tasso, Lamento e Trionfo, Les Préludes, Orpheus, Prometheus, Mazeppa, Festklänge, Héroïde Funèbre, Hungaria, Hamlet, Hunnenschlacht, Die Ideale e Von der Wiege bis zum Grabe - e abriu um fértil caminho à produção de diversos artistas como Claude Debussy (1862-1918), Smetana (1824-1884) e Camille Saint-Saëns (1835-1921), por exemplo.

4 Escrevendo ao seu irmão Modest em setembro de1876, o compositor colocou que: "Como resultado de longa elucubração, de hoje em diante me prepararei para realizar um casamento, com quem quer que esteja disponível. Creio que nossas inclinações sejam o maior e mais insuperável obstáculo à nossa felicidade, e que devemos lutar com todas as forças contra a nossa natureza. Farei o possivel para me casar ainda este ano, $\mathrm{e}_{\mathrm{i}}$ se não tiver coragem de fazê-lo, me libertarei, de qualquer forma, de meus hábitos, e o farei de forma a não ser mais visto na companhia de... Preocupo-me somente em erradicar de mim esta perniciosa paixão".

5 Carta a Anatoly, Florença, 19 de fevereiro de 1878.

6 A esse respeito, ver LUKACS (1982). Para ele, o poeta como autor, controlou os medos, avanços e fragilidades de si mesmo como personagem dentro do plano narrativo.

7 Enquanto a história triste um tinha dito,

Tanto carpia o outro, que eu, absorto

Em piedade, senti letal conflito,

E tombei, como tomba corpo morto.

8 Por passatempo eu lia e meu dileto

De Lanceloto extremo namorados

Éramos sós, de coração quieto.

Nossos olhos, por vezes encontrados,

Cessaram de ler; ao gesto a cor mudara.

Um ponto só deu causa aos nossos fados.

Ao lermos que nos lábios osculara

0 desejado riso, o heróico amante,

Este, que mais de mim não se separa,

A boca me beijou todo tremante,

De Galeotto fez o autor e o escrito.

Em ler não fomos nesse dia avante.

90 tema da Francesca da Rimini, ou o amor adúltero punido com a morte dos amantes, foi bastante profícuo no século XIX e início do século XX. Dentre as várias obras que inspirou, destacamos: no teatro e na ópera, as obras de Paolo Carlini (1825), Saverio Mercadante (1828), Pietro Generali (1829), George Boker (1853), Gabriele d'Annunzio (1901), Stephen Phillips (1902), Sergei Rachmaninoff (1906), Eugene Nordal (1840) e Emanuele Borgatta 1837); na música, além de Tchaikovsky, Arthur Foote (op. 24 - 1890), Antonio Bazzini (op. 77 - 1889) e Paul von Klenau (1913) e nas artes visuais, Joseph Anton Koch (1805), Marie-Philippe Coupin de la Couperie (1812), Jean Auguste Dominique Ingres (18119), Ary Scheffer (1835 e 1855), Gustave Doré (1857), Alexandre Cabanel (1870) e possivelmente Auguste Rodin (0 Beijo - 1888).

Rafael Alves Pinto Junior é arquiteto formado pela PUC- GO, professor do IFET - G0, Mestre em Cultura Visual pela Faculdade de Artes Visuais da Universidade Federal de Goiás e Doutor em História na Universidade Federal de Goiás, Dedica-se à pesquisa sobre imaginário e representações culturais. 